\section{DEL SUBDESARROLLO AL DESARROLLO: EL VIAJE SIN RETORNO DE EDMUNDO DESNOES}

\author{
Yannelys Aparicio \\ Universidad Internacional de La Rioja \\ ORCID iD: https://orcid.org/0000-0003-3074-8741 \\ yannelys.aparicio@unir.net
}

\section{FROM UNDERDEVELOPMENT TO DEVELOPMENT: THE TRIP WITHOUT RETURN OF EDMUNDO DESNOES}

Cómo citar este artículo/Citation: Aparicio, Y. (2020). Del subdesarrollo al desarrollo: el viaje sin retorno de Edmundo Desnoes. Arbor, 196 (797): a567. https://doi.org/10.3989/ arbor.2020.797n3004
Copyright: (c) 2020 CSIC. Este es un artículo de acceso abierto distribuido bajo los términos de la licencia de uso y distribución Creative Commons Reconocimiento 4.0 Internacional (CC BY 4.0).
RESUMEN: La narrativa del cubano Edmundo Desnoes describe los cambios sociales que se dieron en la isla con el triunfo de la revolución en 1959. La pérdida de la libertad significó un proceso de alienación en el individuo y la sociedad, cuya degradación paulatina se observa en la novela Memorias del subdesarrollo (1965), descendiendo desde la animalización a la desintegración. Cuarenta años más tarde, Desnoes publica Memorias del desarrollo (2007) y describe a un protagonista derivado del anterior, en su evolución después de haber dejado la isla y haberse instalado en Nueva York. Sin embargo, la vida en una sociedad desarrollada no curará las heridas mortales abiertas por la represión de la dictadura, porque su identidad ha sido dañada para siempre.

PALABRAS CLAVE: Edmundo Desnoes; cambios sociales; dictaduras latinoamericanas; identidad; Memorias del subdesarrollo; Memorias del desarrollo.
ABSTRACT: The narrative of the Cuban Edmundo Desnoes describes the social changes that occurred on the island with the triumph of the revolution in 1959. The loss of freedom meant a process of alienation in the individual and society, the gradual degradation of which is observed in the novel Memorias del subdesarrollo (Memories of the underdevelopment) (1965), descending from animalization, in the purest Kafkaesque style, to disintegration. Forty years later, Desnoes publishes Memorias del desarrollo (Memories of the Development) (2007) and describes a main character derived from the previous one, in his evolution after leaving the island and settling in New York. However, life in a developed society will not heal the mortal wounds opened by the repression of the dictatorship, because his identity has been irreparably harmed.

KEYWORDS: Edmundo Desnoes; social changes; Latin American dictatorships; identity; memories of the underdevelopment; memories of the development. 
UNA CUBA DESARROLLADA Y UNA CUBA SUBDESARROLLADA

La literatura de los años sesenta en Cuba se debatió entre las concesiones sin fisuras al régimen recién instaurado alrededor de una violenta revolución que sacudió los cimientos de la sociedad insular o la disidencia. Apenas hubo espacio para la autonomía del arte, una opción que se había convertido, desde la segunda mitad del siglo XIX, en uno de los pilares más sólidos de las poéticas contemporáneas en el mundo occidental. Para aquellos que sintieron la necesidad de manifestar su disidencia, los caminos tampoco fueron muy diversos: una acción crítica frontal significaba la salida inmediata del país, y una crítica ambigua, más centrada en lo existencial que en lo específicamente político, permitía a los artistas mimetizar el descontento bajo las formas del existencialismo de posguerra u otras filosofías nihilistas que habían inundado el hemisferio occidental después de los desastres humanos, sociales y políticos de las contiendas mundiales.

Edmundo Desnoes fue el escritor cubano que mejor supo elaborar un discurso que fuera a la vez útil para los objetivos sociales de los partidarios del fenómeno revolucionario y para aquellos desencantados que no se resignaban a esconder su malestar. Su novela Memorias del subdesarrollo (1965) ponía el acento en un concepto que se había acuñado en 1952, cuando el economista francés Alfred Sauvy definió el tercer mundo como el conjunto de países que no pertenecían ni al bloque capitalista ni al bloque del este, y que era la mayor parte del Planeta, los países subdesarrollados, a los que ninguno de los otros dos bloques tenía en cuenta (Sauvy, 1952). Ahora bien, aplicar en 1965 el concepto de subdesarrollo a Cuba se encontraba con dos circunstancias que hacían su situación excepcional. La primera tiene que ver con el hecho de que la isla ya había resuelto, desde sus instancias políticas gubernamentales, asimilarse al bloque del este varios años antes y, por tanto, quizá debería ser considerada miembro del segundo mundo, en terminología de Sauvy, ya que desde su inclusión en ese conjunto político estaba siendo ayudada económicamente por la Unión Soviética, y su economía no podía compararse, en grado de pobreza, a la de la mayoría de los países africanos, asiáticos, centroamericanos y sudamericanos asociados al concepto de tercer mundo.

La segunda particularidad es la que condenaba al país caribeño a una paradoja difícilmente resoluble: Cuba había sido hasta 1958, según los datos macroeconómicos, un país del primer mundo, mucho más avanzado que, por ejemplo, España, Argentina u otros que tradicionalmente siempre habían sido más desarrollados. Solo Venezuela o Uruguay tenían un PIB mayor que el de Cuba en América Latina en esa época. En 1958, según el Proyecto Maddison, el PIB de Cuba era superior al de España, pero en 1963 el de España ya era el doble que el de Cuba, pues la Península había entrado en una clara fase de desarrollismo, mientras que Cuba se hundía con las reformas ejecutadas por el gobierno revolucionario, que incluían la supresión de la propiedad privada, los negocios particulares y cualquier iniciativa económica que no fuera estatal. El último dato que ofrece Maddison, comparando las economías cubana y española es de 2008, y señala un PIB peninsular cinco veces mayor que el insular (Jorrín, 2016, 28 de noviembre). Además del Proyecto Maddison (Maddison Historical Statistics) publicado en 2013, que recoge todo tipo de estadísticas internacionales desde 1926 hasta 2010, los datos que a continuación aportaremos pueden consultarse en el Statistic Year Book of United Nations de 1959, en el Annuaire International d'Education de la UNESCO, de 1959, en Moreno Fraginals (1978), en las publicaciones de la CEPAL/ONU, sobre todo en García Molina (2005, pp. 15-18), y en Mesa Lago (2009, pp. 41-61).

Cuba fue un país que hasta los años cincuenta había batido muchos records de progreso, siendo, por ejemplo, el primer lugar de América Latina y el tercero del mundo en obtener el ferrocarril, el país donde se descubrió el agente transmisor de la fiebre amarilla, gracias al doctor Carlos J. Finlay, quien indicó además su prevención y tratamiento (1881); el primer territorio latinoamericano en desarrollar un sistema de alumbrado público (1889), el primero de América Latina en impulsar el transporte del tranvía y del automóvil (1900), el primero del mundo en implementar la tecnología del discado directo en el teléfono (1906), el primero de América Latina en crear un Departamento de Rayos X (1907), el primer país latinoamericano en realizar un vuelo, entre Cuba y Cayo Hueso (1913), el único país en mantener durante varias décadas la relación uno a uno entre la moneda nacional y el dólar (1915-1958), la segunda nación del mundo en inaugurar una estación de radio (1922), el primer país de América Latina en decretar la jornada laboral de ocho horas, el salario mínimo y la autonomía universitaria (1937), el primer país de América Latina en tener un presidente de raza negra (1940), el segundo país del mundo en emitir formalmente televisión (1950), el primer país del mundo en construir un hotel con aire acondicionado central (1951), etc. 
Todo eso fue desapareciendo con la revolución que triunfó en 1959. En los años cincuenta, los índices de desarrollo, publicados oficialmente por la ONU, daban las siguientes cifras: Cuba era el tercer país de América Latina en consumo de carne por habitante, el segundo con menor mortalidad infantil, el segundo con menor índice de analfabetismo, el de más médicos per cápita, el de mayor porcentaje de viviendas electrificadas y de consumo calórico diario, el segundo del mundo en tener cine en 3D (1957), el segundo en tener televisión a color (1958) y era la economía número 29 del mundo (Esteban y Aparicio, 2015, pp. 185-186). Es cierto que había bolsas de pobreza y focos de desigualdad, y también es cierto que Batista había llevado su proyecto de dictadura a unos niveles amplios de represión, lo que había provocado una revolución en contra de su gestión política, pero la generación de riqueza y el nivel de crecimiento de aquella pequeña isla era una realidad irrefutable.

Por eso, cuando Edmundo Desnoes publicó su novela en 1965, enseguida llamó la atención de críticos literarios, pero también de economistas, sociólogos, politólogos e incluso cineastas, ya que tres años más tarde, en 1968, tuvo lugar una réplica filmográfica que ha sido considerada como la verdadera obra maestra del cine cubano. La obra de Desnoes era una pieza más dentro del conjunto de reacciones de todo tipo que había suscitado el cambio violento de régimen en Cuba. Uno de los teóricos que contribuyó a mantener vivos la discusión y el interés por el nuevo sistema fue el sociólogo de la Universidad de Columbia Charles Wright Mills, quien visitó la isla poco después que Sartre y publicó ese mismo año Listen Yankee. The Revolution in Cuba. Preocupado por la miseria endémica de muchos países latinoamericanos (Brasil, México), por las grandes diferencias económicas entre las clases, la ausencia de una clase media extendida en la mayoría de los países del sur y, sobre todo, por la deriva imperialista de los Estados Unidos sobre Cuba y otras regiones hispanas, alentó a Cuba para continuar un camino experimental y alertó a su país sobre el peligro que corría la isla si caía bajo la influencia del otro imperio, el soviético. Estados Unidos podría impedir esa otra colonización y facilitar a Cuba un camino nuevo sin injerencias del marxismo (Rojas, 2009, pp. 43-45).

Todo ello hizo que, al hilo de los planteamientos de Sauvy, que pretendían colorear a tres bandas el mapa de las relaciones internacionales, en Cuba surgiera un interés muy explícito por el término y el concepto de subdesarrollo, hasta el punto de que en el mismo año en el que se estrenó la película Memorias del subdesarrollo, en el Congreso Cultural de La Habana, algunos de los ponentes invocaron al subdesarrollo como un problema que se colocaba en el crisol «de la nueva identidad crítica del intelectual latinoamericano» (Rojas, 2009, p. 45). Desnoes barajaba, además de la terminología del economista francés, los mismos conceptos que Mills o Sartre para analizar el concepto de subdesarrollo, que eran los que el gobierno cubano establecía para comprometer unas señas de identidad insular que, supuestamente, habrían de extenderse a todo el subcontinente hispánico. La euforia de la nomenclatura, que evocaba también un estilo de vida y de concepción de la sociedad, llegó también a la poética cinematográfica. Ya en la mitad de los años cincuenta habían coincidido en el Centro Experimental de Cinematografía de Roma, como estudiantes, Tomás Gutiérrez Alea (el futuro director de la película sobre la novela de Desnoes), Julio García Espinosa (futuro Viceministro de Cultura para el Cine, en Cuba), Fernando Birri (futuro director de cine, uno de los clásicos de la dirección en Argentina) y Gabriel García Márquez, por entonces un periodista colombiano especializado en temas de cine. Todos ellos se formaron en el neorrealismo italiano, con personajes tan relevantes como Vittorio de Sica o Cesare Zavattini, y en aquella época ya pensaban en crear una plataforma para la creación y difusión del cine latinoamericano. Más adelante, ya instalados en sus países o en otros del subcontinente, desarrollaron la idea de lo que se llamó a partir de los sesenta el tercer cine, que coincidía con la nomenclatura "tercer mundo», y que venía a ser una alternativa al de Hollywood (el primer cine, el de corte capitalista y grandes producciones), y al segundo, el europeo, de autor, más centrado en los problemas humanos, en la profundidad de las historias, que en los efectos y las técnicas.

El tercer cine debería ser el que luchara contra el imperialismo de la industrialización y del gran capital asociado a la producción artística, fijándose en cuestiones sociales y políticas de resistencia y lucha. Pocos meses después de estrenarse la película de Desnoes/Gutiérrez Alea, Fernando Solanas y Octavio Getino publicaron en Cuba el artículo «Hacia un tercer cine», que años más tarde se convertiría, junto con otros ensayos, en el libro clave de la cinematografía latinoamericana (Getino, 1979). Según los autores del artículo, ese tercer cine se centraría en descolonizar la cultura, tratando de inventar lenguajes nuevos para una nueva conciencia y una nueva realidad (Getino, 1979, p. 6). El problema de Desnoes fue que, a pesar de estar incluido por la crítica en ese ámbito de 
difusión del concepto de subdesarrollo y de terceras opciones, su visión no era la de un proletario sino la de un burgués que no sabe muy bien desde dónde y hacia dónde camina.

\section{CONSECUENCIAS DEL SUBDESARROLLO EN MEMO- RIAS DEL SUBDESARROLLO}

En Cuba, novela y película se interpretaron como una crítica al burgués acomodado, sin espacio en la Cuba socialista, a quien le cuesta adaptarse a las nuevas circunstancias que exigen la creación de un «hombre nuevo». En la novela, el conflicto ante el que se debate Sergio, su protagonista, es precisamente el de pensar y actuar como un hombre del primer mundo mientras vive en un país subdesarrollado y tercermundista. El conflicto es más pertinente si se tiene en cuenta que Desnoes no siempre vivió en un país "subdesarrollado», ya que antes de 1959 había elegido Estados Unidos, concretamente Nueva York, para instalarse una temporada, como respuesta burguesa a los conflictos interiores que le generaba la situación política de su país, con la sucesión de regímenes poco convincentes y un grado nada aceptable de corrupción. Lo único positivo de aquella huida, según sus propias palabras en Punto de vista (1967), fue que pudo encontrarse a sí mismo al observarse desde lejos y verse como desdoblado, e integrar después su autoconocimiento una vez comenzado el periodo revolucionario:

Hace apenas dos años y con treinta y cuatro años en las costillas empecé a darme cuenta cabal de lo despistado que andaba después de haber devorado absurdos libros y libros importantes y extraños libros y libros deslumbrantes, y después de haberme ido lo mismo a una isla desierta en las Bahamas, infectada de sutiles y devastadores jejenes, que a vivir en la más gigantesca ciudad del mundo: Nueva York. De nada me sirvió aunque la pasé bien y mal, inseguro. $\mathrm{O}$ mejor dicho: solo me sirvió cuando descubrí un punto de vista para entender lo que había hecho aquí. La experiencia fue necesaria, supongo, pero la revolución cubana fue decisiva. Me obligó a detenerme y asumir mi lugar en el mundo. (Desnoes, 1967, p. 7)

Desnoes, antes de 1959, había vivido en Venezuela, había pasado también un tiempo rodeado de naturaleza, lejos de la civilización, después se había instalado en Nueva York y regresado a La Habana agitados ya los tambores de la revolución y cuando la isla se encontraba en una primera fase de euforia (Luque, 2012, p. 98). Por otro lado, su origen bicultural le hacía portador de ciertas manchas de ambigüedad identitaria, que estarán presentes en sus novelas. De padre cubano y madre estadounidense, el bilingüismo funcionó siempre como la oportunidad de elegir aunque, a menudo, al mejor estilo existencialista, esa libertad no siempre fuera un foco de posibilidades sino de miedos o de indefiniciones. Ya en su primera novela, No hay problema, de 1961, el narrador presentaba al protagonista como un hombre que «Nunca se sentía cómodo en ninguna parte» y anotaba que «Era cubano pero a mundo lo confundían con un norteamericano. Tal vez si hubiera nacido con pelo negro y ojos negros no se sentiría tan improbable y fuera de lugar. Todo en Cuba estaba dominado por la presencia física» (Luque, 2012, p. 98). Asimismo, en su siguiente novela, escrita muy poco antes que sus primeras Memorias..., titulada El cataclismo, el protagonista se resignaba a ser un pobre cubanito subdesarrollao (Luque, 2012, p. 101), a pesar de que soñaba ser otra cosa, más parecida a un hombre del primer mundo.

Sergio Malabre, personaje principal de Memorias del subdesarrollo, se percibe a sí mismo como un extranjero aunque, como sabemos, tampoco era un adaptado en la época anterior, porque su concepto del intelectual burgués latinoamericano siempre había sido el mismo. En el artículo «El mundo sobre sus pies», de mitad de los sesenta, del que se aprovechaban frases para integrarlas en la mesa redonda que se exhibe en la película, Desnoes expresaba un sentimiento que le acompañaría toda la vida, porque es también aplicable al protagonista de la novela de 2007, Memorias del desarrollo, que lleva muchos años viviendo en los Estados Unidos. El cubano asegura en ese texto que aunque él tiene una apariencia blanca e industrializada, ha recibido buena educación y vivido en una familia de clase media habanera, y ha sido durante años perfectamente identificable con su equivalente europeo y estadounidense, tiene la sensación y la conciencia de constatarse solo como una mala imitación del sujeto del primer mundo, y que, haga lo que haga y viva como y donde viva, siempre será inferior al del primer mundo. Y concluye:

Ahora sé que aunque parezca blanco, anglosajón y protestante soy en realidad un negro sureño. Los latinoamericanos somos todos negros. Discriminados, oprimidos, rechazados, ignorados, extranjeros dentro de esa nueva estafa con pretensiones de universalidad: el estilo de vida norteamericano, el gran sueño blanco de los Estados Unidos. (Desnoes, 1967, p. 100)

Como veremos más adelante, el tiempo que pasa entre las primeras Memorias... y las segundas no sirve al protagonista para encontrarse, sino más bien para 
continuar perdiendo detalles de su propia identidad, a pesar de que el cubano pensaba que «todo hispanoamericano se plantea constantemente el problema de su desarraigo y de su identidad», y que "la ausencia de una personalidad cultural lo impelen a recorrer el mundo en busca de patrias espirituales» (Desnoes, 1960, p. 20). Desnoes, consciente de su hibridez, hubiera querido sentirse bien en las dos caras de su constitución cultural, y solventar mediante la síntesis el problema que achaca a todo el orbe hispanoamericano. Sin embargo, ello es solo un deseo, nunca consumado. En una entrevista de agosto de 2018, titulada adecuadamente "De Juan Pérez a Edmundo Desnoes", el escritor cubano-americano aseguraba que le gustaría definirse por las dos culturas, la española y la anglosajona y que quisiera unir a Don Quijote con Hamlet, "crear una combinación de la duda con esa sensibilidad española. Yo soy esa mezcla: el sueño de las locuras de Don Quijote con las dudas de Hamlet» (Rivero y Russell, 2018, 22 de agosto). El nombre completo del escritor es Juan Edmundo Pérez Desnoes, pero él utilizó para firmar sus obras los dos términos que lo identificaban menos con el ámbito cubano y que, según él, lo acercaban a la cultura en inglés.

El personaje de Memorias del subdesarrollo, a pesar del desconcierto creado por los cambios sociales y políticos, y sobre todo a pesar de la opinión del autor acerca de la identidad, decide quedarse a vivir en Cuba, aun teniendo la oportunidad de marchar con su familia rumbo a los Estados Unidos. De este modo, algunas de las interpretaciones sugieren que el Sergio de la historia constituye un fiel retrato de la decadente burguesía, que no era capaz de adaptarse al nuevo modelo social, aunque tampoco se decidía a dar un paso hacia lo desconocido. El dilema acerca de abandonar o no la isla se relaciona probablemente en gran medida con la mirada melancólica hacia épocas anteriores, con el hecho de la que burguesía «con poder económico fijaba en la sociedad pre-revolucionaria abundantes criterios de gusto y consumo, tanto en la vida cotidiana como en el ámbito artístico» (Santana Fernández de Castro, 2010, p. 214). El problema más complicado, que Sergio intuye básicamente, es que el subdesarrollo económico, que ha sido evidente desde los primeros momentos de cambio, deviene subdesarrollo cultural, y afecta a todos los ámbitos de la existencia. A partir de los años sesenta los artistas y escritores tienen que ir, como todos los nacionales, a cortar caña, a las escuelas del campo y, algunos de ellos, a los campos de concentración de las UMAP (Unidades Militares de Ayuda a la Producción), y sus posibilidades de viajar y responder intelectual y for- mativamente a los caminos que la vida burguesa les permitía, ahora quedan sepultados, para que se cumpla el nuevo orden que desdibuja las individualidades, iguala económicamente a todos por debajo y dificulta los viajes y las relaciones con intelectuales y artistas de otros países, así como con sus obras.

Los escritores de la generación de Desnoes, y los artistas o burgueses de la de Sergio, enseguida son conscientes de que su destino miserable lo es, al menos, no tanto como el de aquellos que conforman la primera generación revolucionaria, porque los primeros han podido viajar durante algunos años, conocer otras tierras y otras formas de pensar, han podido leer obras en otros idiomas y de otros países sin cortapisas ideológicas. Y tienen una mente abierta, formada en la libertad y la abundancia. Sin embargo, dice Orlando, amigo de Sergio al comienzo de la película del subdesarrollo, ellos (los más jóvenes) «están más jodidos que nosotros. Ya nosotros por lo menos viajamos y hemos visto museos y experimentado cosas y leído todo lo que nos ha dado la gana». Todo esto contrasta con el espectáculo socializado que impone la revolución con su marketing particular, «que consiste en la escenificación de una utopía en el Tercer Mundo o, más específicamente, en el Caribe, una zona fronteriza donde se capitalizan símbolos turísticos, sexuales, religiosos y revolucionarios como atributos de una comunidad políticamente alternativa» (Rojas, 2009, p. 29).

El mérito de Desnoes consiste quizá en mostrar abiertamente, por primera vez dentro del proceso revolucionario, la preocupación existencial de tantos pensadores cubanos que se enfrentaban a la duda, debatiéndose ante la disyuntiva de vivir entre el pasado y el presente y sin saber exactamente qué rumbo tomar. Era este, en última instancia, el desasosiego por el futuro de la literatura en un país socialista, subdesarrollado y en plena construcción de una sociedad en la que "todo lo que nos rodea está hundido en el subdesarrollo. Hasta los sentimientos del cubano son subdesarrollados: sus alegrías y sus sufrimientos son primitivos y directos, no han sido trabajados y enredados por la cultura. La Revolución es lo único complicado y serio que les ha caído en la cabeza a los cubanos. Pero de aquí a que nos pongamos al día con los países civilizados pasarán muchos años» (Desnoes, 2006, p. 36). Pero ¿qué significaba para el protagonista de Memorias... ponerse al día? ¿Era lo mismo que para el régimen? Para entonces, en la isla, el Che Guevara parecía haber descubierto, en su obra El hombre y el socialismo en Cuba (1965), que la culpa de que muchos 
intelectuales y artistas no siguieran por el camino correcto radicaba en el hecho de que «no eran auténticamente revolucionarios» (Guevara, 1968, p. 636).

A partir de entonces se llevó a cabo en la nación una fuerte campaña para adoctrinar a todos aquellos que no fueran conscientes de la necesidad de apoyar el nuevo proyecto. Si se quería permanecer protegido había que ser revolucionario, término que en aquel momento resultaba un tanto confuso para algunos. De hecho, en el Congreso Cultural de 1968, Ambrosio Fornet declaraba que en la Cuba de esos años se leía y publicaba a Kafka, a Proust, a Joyce, se proyectaba el cine de Visconti, Antonioni, Bergman o se exhibía arte vanguardista y abstracto, o netamente contemporáneo y occidental, pero, como dice Rojas, "lo cierto es que descolonizarse y desarrollarse implicaba para aquellos intelectuales algo más que ser socialistas heterodoxos que admiraban las vanguardias occidentales. No bastaba con definirse como "socialistas cubanos" y, a la vez, mantenerse interesados en la producción cultural de Occidente: esa legítima posición era vista por sus superiores y por ellos mismos como una contradicción o una ambigüedad» (Rojas, 2009, p. 51). La contribución de Fornet al Congreso invitaba a los revolucionarios a ser contundentes, manifestarse con claridad y dureza, alejarse de la suavidad de las «vírgenes» o los «arcángeles» para proceder a provocar un incendio, con virulencia. (Fornet, 1977, p. 35)

El debate sobre el papel que debían ocupar los intelectuales y artistas en el campo cultural y literario de la isla, y por ende de toda América Latina, estaba servido. Aquellos que se alinearon con la propuesta incendiaria de Fornet ya sabían a qué atenerse, y los que desearon una libertad plena para establecer una independencia absoluta entre el poder y el arte tomaron el camino del exilio. Pero Desnoes eligió muy hábilmente el terreno pantanoso de la ambigüedad y de la ironía, ya que la novela de 1965 «no se planteaba como vehículo para la adhesión de ideas, sino como exposición crítica e irónica de los diferentes discursos que entraban en tensión en la sociedad cubana de la época» (Peris, 2011, p. 425). Por eso, Memorias... se interpretó con argumentos sólidos tanto desde el punto de vista de una crítica feroz a la burguesía acomodada que había perdido su lugar en la nueva sociedad como a la dictadura que impedía al artista manifestarse con libertad. En este contexto, el personaje de Memorias del subdesarrollo monologa, como una criatura abandonada, a veces sin más finalidad que la de observar y describir su entorno, aunque en ocasiones también se autoanaliza: «Me da una sensa- ción extraña al caminar por las habitaciones; la casa se está convirtiendo en una caverna» (Desnoes, 2006, p. 30). Sergio se describe y proyecta como un mero observador, haciendo que sus exposiciones sean cada vez menos profundas o elaboradas. Así, al explorar su cuerpo afirma: «Fijándose en los pies uno ve que está muy cerca, que es un animal» (Desnoes, 2006, p. 25), y un poco más adelante: «esta mañana me asombró el eructo tan ruidoso que solté cuando terminé de tomar el café con leche (...), me estoy convirtiendo en un animal» (Desnoes, 2006, p. 31). Para entender mejor los efectos de la animalización, debemos hacer hincapié en la naturaleza y el alcance del proceso comunicativo. En su obra Política, Aristóteles establece que el hombre tiene uso de razón y lenguaje, lo que le confiere una voz, que sirve para mostrar las penas y las alegrías, para decir qué es lo que está bien y lo que está mal, y por ellos es esencialmente diferente a los demás animales (Simón Abril, 1910, pp. 15-16).

El concepto de "animal racional» aristotélico está planteado con claridad en el comienzo del relato y de la película, porque el diletante y sus amigos analizan la situación con ciertos visos de objetividad y manifiestan una inteligente capacidad de análisis pero, en el momento del autoesclarecimiento, Sergio observa que va perdiendo cualidades abstractas, inmateriales, incluso racionales, porque el examen de las reacciones corporales le coloca en otro nivel, más animalizado. Cuando eso comienza a ocurrir, en las primeras ocasiones Sergio trata de corregir los reflejos instintivos: "Como no hay nadie en casa no me aguanto nada. Me acordé de mi padre soltando peos y eructando solo en el portal los domingos (...). No puedo permitir que esto vuelva a pasar. Aunque no haya nadie en la casa debo comportarme como un hombre civilizado. Me avergonzaría terriblemente que alguien hubiera oído mi eructo de bestia satisfecha» (Desnoes, 2006, p. 31). Sin embargo, hacia la mitad de la novela, el protagonista va evolucionando hacia la pérdida de ciertos criterios y valores, pasando a proyectar una voz imparcial, que refleja los vaivenes de su existencia sin perseguir mucho más que la satisfacción de sus necesidades vitales: dar rienda suelta a sus pasiones, alimentarse, incluso convivir, mientras es testigo del transcurrir del tiempo, sin trazarse ya aspiraciones ni propósitos de lucha. Así, conecta ideológicamente con cierta corriente existencialista de mitad de siglo, que se inauguró en Cuba alrededor de la obra y las actitudes de algunos intelectuales y artistas relacionados con el entorno de Orígenes, unas dos décadas antes de que Desnoes produjera su obra literaria de los años sesenta. Como ha hecho notar Rojas, 
Orígenes se debatía entre el horror vacui de Pascal y la nada que fluye de Nietzsche. Dos alternativas plenamente inscritas en la deconstrucción de la razón occidental: el AntiDescartes y el AntiHegel, descritos por Albert Camus en El hombre rebelde, cuyo fragmento sobre el nihilismo fue traducido por Rodríguez Feo para un número de 1952. Esta plataforma (...) permitió ciertas aproximaciones al existencialismo y, en especial, a Martin Heidegger, de quien Piñera Llera tradujo el pasaje de ¿Qué es la metafísica? En el verano de 1949 (Rojas, 2008, p. 296).

Desnoes, ligeramente posterior a esta generación bicefálica en cuanto al origen de ciertas actitudes existenciales, será algo más cercano al existencialismo sartreano, y más afín a esa «nada que fluye», materia básica del pensamiento de los franceses de la posguerra mundial, y alimento de una gran parte de la novelística cubana de los sesenta, (Menton, 2002, p. 410) y también en la española y en otras tradiciones literarias (Jiménez Martínez, 2011). Pero la animalización kafkiana no está solo representada en las Memorias del subdesarrollo, escrita y publicada en un momento de auge de corrientes existencialistas en Cuba enfrentadas al triunfalismo y mesianismo del gobierno revolucionario, un momento en que no pocos escritores comenzaban a considerar que en Cuba se estaba dando un proceso de animalización del individuo, encerrado en una cárcel de naturaleza panóptica, fácilmente equiparable al contexto de numerosos relatos del checo. También hay reflejos del mismo universo en su siguiente novela. Cuarenta años después de publicar Memorias del subdesarrollo, el lector se encuentra a otro alter ego creado por Desnoes, ya en la tercera edad, quien nos relata las vivencias de la segunda etapa de su vida en Europa y Estados Unidos. Memorias del desarrollo podría ser considerada como una segunda parte, donde se presenta a un Edmundo mucho más escéptico y deshumanizado, y sorprende la estampa de un hombre que tampoco logra encontrar su sitio, su libertad plena, su buscada y deseada identidad, en la cuna del desarrollo: Nueva York.

Sergio, en las primeras Memorias... manifiesta un comportamiento cada vez menos racional y, a su vez, más animalizado, dejando gradualmente de recordar a sus padres o su ex mujer. "Noemí a mi lado y yo no podía sentir nada tierno (...) Estamos desnudos en la cama, indefensos, dos animales sin pelo, sin músculos fuertes, sin protección, desvalidos» (Desnoes, 2006, p. 141). En una visita a la casa de Hemingway, en La Habana, ante el retrato de Ava Gardner, Sergio explora detalladamente su objeto de placer: «tenía los pies muy grandes (...). Es lo único que podemos hacer no- sotros los subdesarrollados, masturbarnos con fotos de las grandes hembras del mundo" (Desnoes, 2006, p. 67). Esta vida diferente, y cada vez más, de lo que hasta entonces ha sido corriente, y que hace al animal diferenciarse del hombre, consiste en la «creación de un interregno, un pequeño territorio paralelo, subterráneo o por fuera de la luz» (Garbatzky, 2017, p. 51) en el que la existencia del animal (o lo animalizado) «exige la invención del margen, los recovecos donde pueda existir e incluso donde pueda visualizarse furtivamente, brillar» (Garbatzky, 2017, p. 52).

El individuo exhibe una voz cada vez más imprecisa, en la medida en que avanza su desidia: «No tengo ganas de hacer nada. Estoy aquí sentado ante la máquina de escribir porque me duele la cabeza de tanto dormir. Me siento intoxicado de sueño (...). Y solo podemos escribir la vida o la mentira que realmente somos. Ahora tengo ganas de tirarme en la cama. Me voy» (Desnoes, 2006 , p. 23). Se evidencia aquí el cansancio y el desarraigo, algo que se une al uso del tiempo como algo fenoménico y no tanto cronológico, que aparece cuando Sergio tiene la intención de poner la fecha cada vez que se sienta a escribir pero luego se da cuenta de que eso no tiene sentido, que es una tontería (Desnoes, 2006, p. 30). Es parte del discurso de corte existencialista sartreano, que pone «en primer plano los vacíos del relato», que media "entre cada momento de escritura» $\sin$ aparecer descrito en ella, pero que determina «las transformaciones en su tonalidad emotiva» (Peris, 2011, p. 426), y que se manifiesta también en el modo de observar al resto de los cubanos que comparten con el protagonista el proceso de carnavalización: «Es un juego enloquecedor fijarse en una parte del cuerpo de las personas; las orejas, por ejemplo, los vientres. Y ni hablar de las formas, posiciones y tamaños de los fondillos femeninos (...) La gente me dio la impresión de desvalidos, indefensos, semilampiños, precariamente balanceados en dos patas» (Desnoes, 2006, p. 132). Las diferencias cada vez mayores entre lo espiritual y lo corporal van a acentuar la distancia entre lo humano y lo animal, en ese proceso de conversión hacia lo físico en detrimento de lo racional. Cuerpos carnavalizados, al decir de Bajtin, desprovistos de sensibilidad inmaterial y condenados al mero movimiento físico (Bajtin, 2002, p. 273). Al hilo de estas reflexiones, Peris en su estudio sobre la obra de Desnoes de 1965 observó que se ajustaba a esa definición del cuerpo como «espectáculo grotesco», cercano a lo que la «cultura burguesa iba a borrar de su representación estilizada del cuerpo humano y que ponía el acento en las partes del cuerpo abiertas as exterior, en sus orificios, protuberancias y salientes (Peris, 2011, p. 430). 


\section{UN DESARROLLO MATERIAL SIN RECUPERACIÓN IDENTITARIA}

La idea de la muerte como solución necesaria, o de la imposibilidad de redención, emergen hacia el final de la novela del subdesarrollo. Son consecuencias lógicas del recorrido existencial que se ha trazado. El vacío y la muerte admiten cierto grado de identificación en la medida en que el vacío nombra el No-Ser. Nombrar el término de la vida es pasar de lo articulado (el Dasein heideggeriano como Ser en el mundo, es decir, Sein-in-der-Welt), a la desarticulación, a la «deconstrucción de la ligazón del sujeto con la totalidad de referencias posibles» (Laera, 2013, p. 117). Al final de la novela del subdesarrollo, Sergio desvela, como único propósito, la huida: «Salí, regresé. No soporto la casa ni la calle (...) Una isla es una trampa, la Revolución nos cogió a todos aquí dentro. No sentí ningún alivio mirando el mar. No veía nada (...). Terminó la vida, tengo que soltarlo todo: el mundo se abre debajo de mis pies, me hundo en el vacío, me vuelvo loco» (Desnoes, 2006, pp. 145-147). Y aunque no muere, se produce un hecho curioso, pues el narrador desaparece de la historia en el último capítulo, titulado "Yodor», cediendo así el protagonismo a un tal Paco López, que con mezcla de orgullo y nostalgia cuenta su experiencia en la construcción de un muñeco mecánico capaz de caminar, hablar y fumar. Luego, poco a poco, el personaje va describiendo sus peripecias al tratar de dar a conocer su invento, así como las carencias a las que se enfrentó debido a la escasez de piezas para mantener el invento en buen estado. EI capítulo final de Memorias del subdesarrollo se separa totalmente del resto de la historia, alejándose de la vida de Sergio, quien ya no analiza a sus coterráneos, ni reflexiona acerca de su presente, ni transmite sus sentimientos. Sin embargo, resulta interesante cómo la nueva voz narrativa constata la realidad cubana que, anteriormente, había sido descrita por Malabre. El cambio de voz narrativa es también el símbolo de la desarticulación existencial de Sergio, en el sentido heideggeriano del que hablábamos.

Como si se tratara de una metáfora de la revolución cubana, Paco describe la euforia ante las perspectivas del inicio, el éxito de la empresa, la repercusión internacional (en este caso en Nueva York), la fama, luego la decadencia, la carencia de recursos, la precariedad que precedería a los cambios sociales y el silencio ante los temas que tratasen sobre política y, para demostrar la veracidad del argumento, el personaje recurre a un álbum de fotos, prueba irrefutable de todo lo expuesto. Luego desvela el anhelo de libertad, la búsqueda de una salida, que en este caso sería la marcha a Estados Unidos y, en contraste, la imposibilidad de lograr dicho anhelo a corto plazo. Malabre ya no emitirá más testimonios, su monólogo termina en el penúltimo capítulo, como si no fuese capaz de articular palabra alguna y, por tanto, recurriese a otra voz que permitiera enunciar nuevas declaraciones. Memorias del subdesarrollo cierra la historia con la incógnita acerca del destino de Sergio, aunque las afirmaciones de Paco sugieren la inevitable ruptura: «EI muñeco ya no existe. Le entré a hachazos. Un día cogí un hacha y lo hice pedazos. Lo desbaraté» (Desnoes, 2006, p. 180). El destino de Yodor es, finalmente, metáfora de los de Paco y Sergio: "Yodor era muy grande para Cuba, muy caro, era un muñeco incosteable» (Desnoes, 2006, p. 181). El sinsentido del giro final de la novela remite al absurdo de la vida. El desplazamiento estructural y temático remite a la ausencia de centralidad existencial, que culmina en la desaparición de la voz original, y de la del muñeco, la falsa voz, que nunca habría podido sustituir a la verdadera. La respuesta final es el silencio, porque es muy evidente la conexión del vacío de la persona con el colectivo. El fracaso del individuo habla del fracaso del sistema, que quizá en los años sesenta, cuando Desnoes terminó la novela del subdesarrollo, no era tan evidente para toda la sociedad, pero que en el cambio de siglo ya no generaba ninguna duda.

Al retomar la pista del nuevo alter ego, cuatro décadas más tarde, ya instalado en Manhattan, Nueva York, y convertido en un ciudadano estadounidense, Memorias del desarrollo evidenciará, contrariamente a lo que se esperaría del individuo asentado en una de las ciudades más prósperas del mundo, a un hombre aún más desamparado que en el subdesarrollo, y con la única certeza de que no logrará encauzar su camino: «Corra o no corra -dice el narrador-, jamás llegaré a ninguna parte» (Desnoes, 2007, p. 11). El personaje principal se sabe atrapado en una situación hostil de la que no intenta escapar; por el contrario, aprecia la soledad que lo llevará al final: «Quiero líbrarme de las muletas del picolísimo nombre que he logrado. No quiero que recuerden los libros que publiqué. Ya no tengo la seguridad y el prestigio de un trabajo bien remunerado, ni la húmeda intimidad de una mujer, ni siquiera los sacudimientos de una entretenida conversación con amigos. El que habla solo persigue hablar con Dios un día» (Desnoes, 2007, p. 12). La intertextualidad machadiana refleja el estado interior de una persona que ansía encontrarse a sí misma en una autocontemplación satisfactoria, de identidad recobrada, aunque ello no parece posible. 
En la historia del desarrollo, Desnoes dibuja a un hombre que lleva sobre sus hombros la carga de varias décadas de penuria en Cuba. En este sentido, el personaje maneja datos concretos -en él no hay incertidumbre sino desidia-, y es capaz de contemplar el pasado, analizar los errores cometidos y sintetizar la evolución del país, intuyendo que ya está todo perdido. Edmundo, un nuevo Sergio, siente la culpa de los irreparables pecados de la etapa del subdesarrollo: «Los detalles son más importantes que la totalidad; la totalidad es una abstracción. Debí haberme iluminado en el preciso instante en el que desaparecieron del mercado el papel sanitario y los desodorantes (...). Debí haberme iluminado especialmente después de mi primer viaje a Checoslovaquia y Alemania del este (...). El fracaso del comunismo saltaba a la vista desde cada objeto, habitación, edificio, desde cada arreglo económico y social -pero en mi estúpida coraza ideológica no quería reconocer el error del proyecto» (Desnoes, 2007, pp. 88-89).

Y nuevamente, como ya ocurría en las primeras Memorias..., el ámbito de los animales se antoja recurrente, con una diferencia: si en el subdesarrollo se produjo un proceso de animalización, en el desarrollo se ubica la imagen del animal como espejo identitario del narrador: «Un perro: pensé mientras me acostumbraba a convivir con solo mi imagen en el espejo (...), el perro es la única criatura en toda la creación que ha establecido una verdadera intimidad con la mujer y con el hombre (...); el perro vive en simbiosis con los humanos. Por eso pensé que debía conseguirme un perro" (Desnoes, 2007, pp. 12-13). Además, otros animales se harán familiares al protagonista, que vivirá una terrible paradoja: en uno de los lugares más poblados de la tierra y con mayor diversidad étnica, social y económica, lo único reseñable es la confluencia con ciertos animales: «Un groundhog, una obesa marmota se deleita en el césped (...) en cuanto me ve abrir la puerta huye (...) Tengo la sospecha, me temo que la marmota se ha establecido, vive bajo la cabaña» (Desnoes, 2007, p. 185)

Memorias del desarrollo sorprende en sus últimas páginas con una voz nueva: una hija natural de Edmundo cuenta ciertos episodios de la revolución cubana que se le habrían escapado a su padre. A través de Natalia Desnoes, el lector conoce detalles de los últimos días del personaje, cuya realidad se reduce a un cuerpo aletargado e inmóvil: "¿Qué haces ahí tirado como un perro? -es todo lo que se me ocurrió contestarle en ese momento (...). El cuerpo que vi tendido ahí solo sobre la hierba e incapaz de moverse, de levantarse, ese era el cuerpo de mi padre» (Desnoes, 2007, p. 221). El alejamiento del mundo humano encamina al personaje hacia el deseado final: «Es posible dormir para siempre y existir a lo largo de una eternidad. Vivir y respirar sedoso en el aire. Quieta. Quieto» (Desnoes, 2007, p. 191). Edmundo parece, finalmente, haber llegado a una conclusión: la única solución es la liberación platónica del cuerpo: sin cuerpo no hay prisión, ni desencanto, ni sufrimiento. Animalización, pérdida de voz, corporalidad sin conciencia, desintegración: este es el proceso que conforma la búsqueda inútil de una identidad esquiva. ¿Qué implica este final? Si comparamos las dos Memorias..., observamos numerosos paralelismos inquietantes. El proceso de animalización y aniquilación de lo humano es similar. Desnoes salió de Cuba en 1979 para instalarse definitivamente en Nueva York, buscando un refugio para su identidad perdida por la falta de libertad de la dictadura, por las incomodidades provocadas por un sistema alienante, que lo llevaban a una progresiva desaparición como ser humano.

Supuestamente, ese cambio de ubicación debería haber sido el detonante de un reencuentro identitario, ya que la condición anfibia o híbrida del autor podría facilitarle la asimilación a un nuevo tipo de sociedad, en el que la libertad está visible desde casi toda la extensa ciudad en forma de estatua. Desnoes por fin podría superar haber sido alguna vez Pérez. De ese modo, Edmundo debería haber podido superar haber sido Malabre alguna vez. Pero ninguna de esas cosas ocurrió. La revolución había determinado, parece que de un modo definitivo, la identidad individual. No había marcha atrás. La alienación había deconstruido y pulverizado el interior de la persona, dejando apenas la carcasa, el ensamblaje exterior. Y el proceso no era reversible en el ámbito del desarrollo. La relación entre posibilidad espiritual y posibilidad material nunca fue directa.

De la misma forma que, en el aspecto macroeconómico, el país no podría volver a la situación que hemos descrito, anterior a 1959, aunque hubiera un cambio radical de gobierno, en el microcosmos de la persona tampoco es posible el retorno. Ningún Ave Fénix renace de sus cenizas cuando un sistema político ha quebrado los principios básicos de la dignidad humana establecidos por la libertad de pensamiento, de palabra, de acción. Aquel que aprendió, a la fuerza, a no ser libre en Cuba, nunca aprenderá a ser libre en un lugar adecuado para ello. 


\section{BIBLIOGRAFÍA}

Bajtin, M. (2002). La cultura popular en la Edad Media y el Renacimiento: el contexto de François Rabelais. Madrid: Alianza Editorial.

Desnoes, E. (1960). ¿Evolución o Revolución? Lunes de Revolución, 65, pp. 20-21.

Desnoes, E. (1967). Punto de vista. La Habana: Instituto del Libro.

Desnoes, E. (2006). Memorias del subdesarrollo. Sevilla: Mono Azul.

Desnoes, E. (2007). Memorias del desarrollo. Sevilla: Mono Azul.

Esteban, Á. y Aparicio, Y. (2015). Pretecnología en tiempos tecnológicos: «Rumba Palace» de Miguel Mejides. En Noguerol Jiménez, F., Pérez López, M. Á. y Sánchez Aparicio, V. (coords.). Letras y bytes. Escrituras y nuevas tecnologías. Kassel: Reichenberger, pp. 185-203.

Fornet, A. (1977). El intelectual en la Revolución. En Benedetti, M., Carpentier, A., Sánchez Vázquez, A., Cortázar, J., Bernet, M., Rama, Á., Aguirre, M. Literatura y arte nuevo en Cuba. Barcelona: Laia, pp. 33-39.

Garbatzky, I. (2017). Supervivencia de las cucarachas. Kafka en Cuba a finales del siglo XX. 452으, 17, pp. 47-65.

García Molina, J. (2005). La economía cubana desde el siglo XVI al XX: del colonialismo al so- cialismo con mercado. México: CEPAL.

Getino, O. (1979). A diez años de "Hacia un tercer cine». México: Universidad Nacional Autónoma de México.

Guevara, E. (1968). Obra revolucionaria. El hombre y el socialismo en Cuba. México: Editorial Era.

Jiménez Martínez, M. (2011). Teoría y crítica de la novela existencialista. Madrid: Universidad Complutense.

Jorrín, J. G. (2016, 28 de noviembre). Cuando Cuba era igual de rica que España antes de Fidel Castro. El Español. [En línea]. Disponible en https:// www.elespanol.com/invertia/economia/macroeconomia/20161127/173983093_0. html

Laera, R. (2013). La preocupación por la muerte. Problemata, 4 (1), pp. 110-133. https:// doi.org/10.7443/problemata. v4i1.15304

Luque, A. (2012). Edmundo Desnoes, un "voyeur» del siglo. Cuadernos Hispanoamericanos, 744, pp. 97-104.

Menton, S. (2002). Caminata por la literatura latinoamericana. México: Fondo de Cultura Económico.

Mesa Lago, C. (2009). Balance económico-social de 50 años de Revolución en Cuba. América Latina Hoy, 52, pp. 41-61.
Moreno Fraginals, M. (1978). El ingenio: complejo económico social cubano del azúcar. La Habana: Editorial de Ciencias Sociales.

Peris, J. (2011). Ironía, ambivalencia y política en Memorias del subdesarrollo, de Edmundo Desnoes. RILCE. Revista de Filología Hispánica, 27.2, pp. 424440.

Rivero, M. y Russell, L. (2018, 22 de agosto). De Juan Pérez a Edmundo Desnoes. OnCubaNews, [En línea]. Disponible en https://oncubanews.com/cultura/de-juan-perez-a-edmundo-desnoes/

Rojas, R. (2008). Motivos de Anteo. Patria y nación en la historia intelectual de Cuba. Madrid: Editorial Colibrí.

Rojas, R. (2009). El estante vacío. Literatura y política en Cuba. Barcelona: Anagrama.

Santana Fernández de Castro, A. (2010). Literatura y cine. Lecturas cruzadas sobre las Memorias del subdesarrollo. Santiago de Compostela: Universidad de Santiago de Compostela.

Sauvy, A. (1952). Trois mondes, une planéte. L'Observateur, 118, p. 14.

Simón Abril, P. (trad.) (1910). Aristóteles. La Política. Madrid: Ediciones Nuestra Raza. 